\title{
Digital Testing of High-Voltage Circuit Breakers
}

\author{
Pieter H. Schavemaker, Lou van der Sluis, ${ }^{l}$ Renê P.P. Smeets, ${ }^{2}$ Viktor Kertész ${ }^{2}$
}

(t) circuit breaker is a switching device that the American National Standards Institute (ANSI) defines as: "A mechanlcal switching device, capable of making, carrying, and breaking currents under normal circuit conditions and also making, carrying for a specified time, and breaking currents under specified abnormal circuit conditions such as those of short circuit." ANSI adds, as a note: "A circuit breaker is usually intended to operate infrequently, although sometypes are suitable ior frequent operation."

Higl-voltage circuit breakers play an important role in transmission and distribution systems. They must clear ffults and isolate faulted sections rapidly and reljably. In short, they must possess the following qualities:

- In closed position, they are good conductors

- In open position, they are excellent insulators

- They can close a shorted circuit quickly and safely without uslacceptable contact erosion

- They can interrupt a rated short-circuit current, or lower current, quickly without gencrating an abnormal voltage.

The only physical mechanism that can change in a short period of time from a conducting to an insulating state at a certain woltage is the arc. It is this principle on which all circuit breakers are based.

The first circuit breaker was developed by J.N, Kelman in 1901. It was the predecessor of the oil circuit breaker and capable of interrupting a short-circuit current of 200 to $300 \mathrm{~A}$ in a $40 \mathrm{kV}$ system. The circuit breaker was made up of two wouden barrels containing a mixture of oil and water, in which the contacts were inmersed. Since then, circuit breaker design has undergone a remarkable development. Nowadays, one pole of a circuit breaker is capable of interrupting $63 \mathrm{kA}$ in a 550 $\mathrm{kV}$ network, with $\mathrm{SF}_{\text {in }}$ gas as the arc quenching medium.

Still, the design of a circuit breaker is not only a sci-

${ }^{2}$ Delft Iniversity of Techuology

${ }^{3}$ KTMM :-igh-P'ower Laboralory ence but also an art. Because of the complex phenomena involved, circuit breaker prototypes have to be verified by practical tests in the laboratory. In high-power laboratories, the abjilty of circuit breakers to interrupt shortcircuit currents is verificd in test circuits, which are in 


\section{Circuit Breaker Switching and Arc Modeling}

The switching action, the basic function of the circuit breaker, refers to the change from conductor to insulator at a certain voltage. Before interruption, the (shortcircuit) current flows through the arc channel of the circuit breaker. Bccause of the nonzero resistance of the arc channel, this short-circuit current causes a voltage across the contacts of the circuit breaker: the arc voltage. The arc behaves as a nonlinear rosistance. Thus, both arc voltage and arc current cross the zero-value at the same time instant. If the are is cooled sufficiently at the time the current goes through zero, the circuit breaker interrupts the current, because the electrical power input is zero. During current interruption, the arc resistance increases from practically zero to almost infinite in microseconcls. Immediately after current interruption, the transient recovery voltage builds up across the circuit breaker. As the gas mixture in the interelectrode space does not change to a completely insulating state instantaneously, the arc resistance is finite at that time, and a small current can flow: the post-are current.

Black-box arc models are mathematical clescriptions of the electrical properties of the arc. This type of model does not simulate the complicated physical processes inside the circuit breaker but describes the electrical properties of the circuit breaker. Measured voltage and current traces are used to extract the parameters for the differential equations describing the nonlinear resistance of the electrical arc for that specific measurement.

\section{Digital Testing}

The functionality of high-voltage circuit breakers is tested in high-power laboratories. Due to the necessary power and the physical size of the equipment, testing is rather expensive and time consuming. in order to obtain as much information as possible about the degradation and operating linits of the circuit breaker from the costintensive tests, a project started with the following partners: KEMA High-Power Laboratory, The Netherlands; Delft University of Technology, The Netherlands; Siemens AG, Germany; RWE Energie, Germany; and Laborelec cv, Belgium. This project is sponsored by the Directorate General XII of the European Commission in Standards, Measurements, and Testing Program under contract number SMT4-CT96-2121. The project is aimed at developing digital testing of high-voltage circuit breakers, i.e., a software product for testing of a model of such a device, once its characteristic fingerprints are obtained from refined measurements during standard tests. Digital testing offers a wide range of new possibilities for users, manufacturers, standlardizing bodies, and test laboratories for fine tuning circuit breaker abilities in relation with standards and real power systems. Some developments arc:

- Evaluation of the relevance of future standards with respect to real power systems
- Evaluation of the relevance of future standards for different circuit breaker technologies and cxtinguishing melia

- Estimation of the circuit breaker's interrupting limit

m Reduction of full-scale testing in high-power laboratories

- Iclentification of network topologies that can puse special difficulties to a circuit breaker

m Acceleration of development of new circuit breaker clesigns

- Monitoring the aging processes of circuit brcakers in service

- Expansion of services for high-powor laboratories.

The steps followed so far to enable digital testing are clescribed in the following sections. At the end of the article, examples of digital tosting are presented.

\section{Measurements and Data Analysis}

Itigh-resolution measurements of current and voltage in the critical period around short-circuit current zero must supply the necessary parameters, characterizing the breakers' behavior. A tailor-made high-frequency measuring system was realized for this purpose. This system consists of a number of battery-powered, singlechannel, $40 \mathrm{MHz}, 12$ bit AD converters, each storing the data temporarily in on-board local RAM (256k samples each). The concept of on-site data storage is neccssary for reaching a maximum overall system bandwidth. Cables to the current and voltage sensors can thus be kept very short, and the system can operate on floating potential. The arc voltage is measured with standard broad-band RCR-type voltage dividers; current is measured with a special Rogowski coil. After the remote RAM is filled, data is transmitted serially through optical fibers to the processing unit in the command center. The greatest chailenge with respect to developing the equipment in this application design ties in the electromagnetic compatibility, since the microelectronics has to function in an extremely hostile environment of intense EM fields of various origin.

The system relies heavily on digital signal processing methods for reconstructing the actual voltage and current signals from the raw sensor output. On the one hand, this has to do with the specific frequency response of the sensors and on the other hand, with corrections needed for the (reproducible) induced voltages and capacitive current that distort the measured signals. Tests in various laboratorics have proven that the system can measure post-arc current as small as $50 \mathrm{~mA}$, microseconds after the interruption of many tens of $\mathrm{kA}$.

Data analysis software has been produced to carry out the signal reconstruction practically on line during the tests (Figure 1), and to cvaluate the performance of the test object. Even the newest professional multipurpose mathematical or laboratory software is not competitive to this custom-made soltware considering 


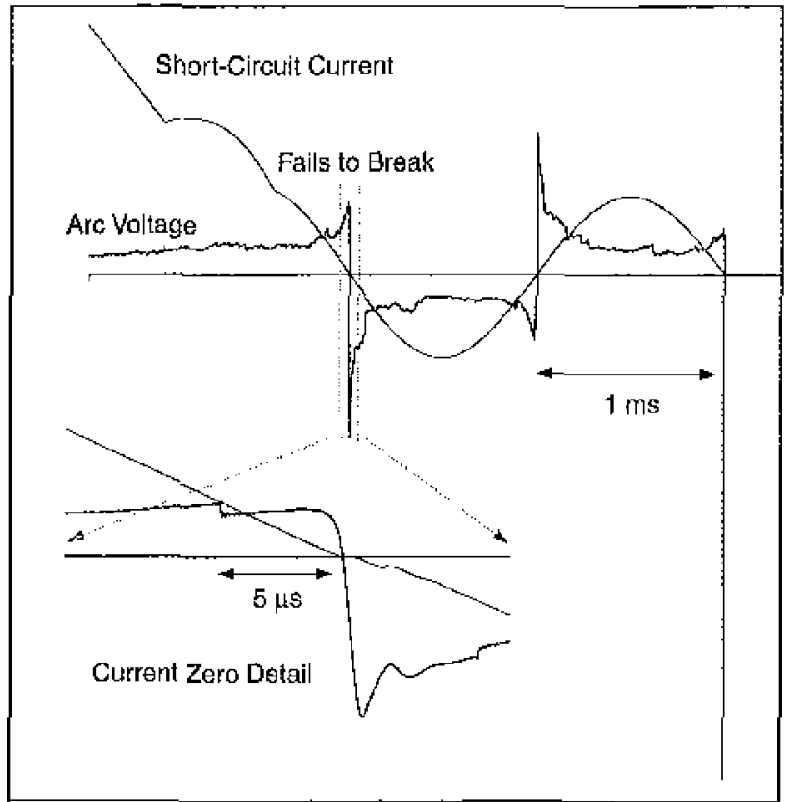

Figure 1. Voltage and carrent measurement data

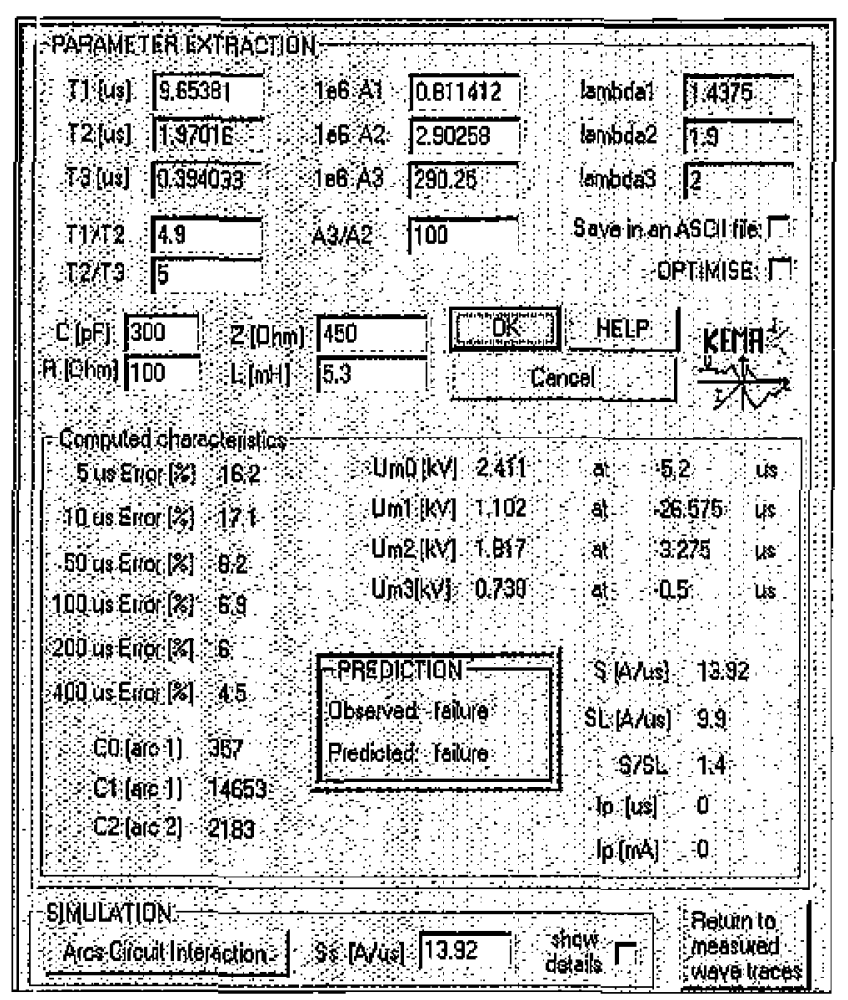

Figure 2. Parameter extraction software

flexibility and specd in visualizing and data processing of practically unlimited amount of measured data in a user-friendly way.

After an extensive series of the most critical fault interruption duty for circuit breakers (the so-called "short-line fault," see the section on "Applications of Digital Testing"), a test database from various types of com-

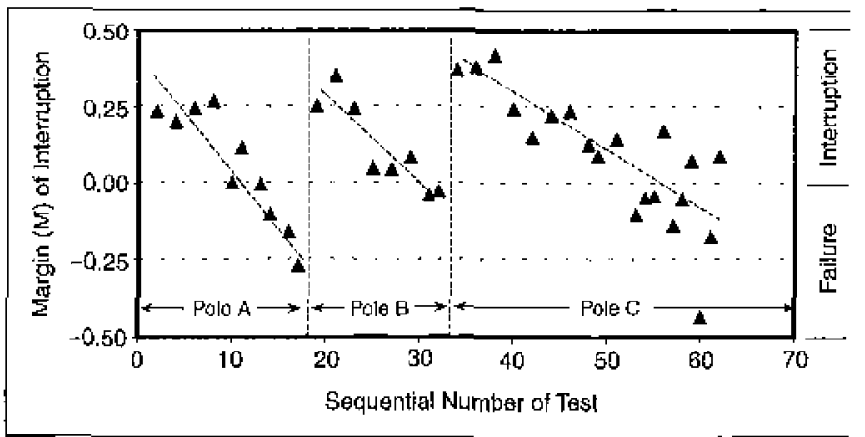

Figare 3. Degradation of the circuit breaker poles

mercially available circuit breakers was set up. With this experimental material, an empirical arc model based on classical arc models was validated that gave very good coverage of the observed processes. From the total number of ( $>250)$ interruption attempts, the rosult of the attempt (failure/success) was predicted correctly in more than $90 \%$ of the cases by evaluating the characteristics of the arc behavior with the model.

The model has a set of (three) parameters, which are extracted automatically during the evaluation of each test (Figure 2). Automated analysis of the collection of all the parameter sets (in other words, the breakers' "fingerprints") obtained from a whole series of tests makes it possible to evaluate various physical quantities as a function of test conditions.

The aim of using this method is to quantify the breaker performance (the margin $M$ of interruption), indicating how successful the breaker passed the test $(M>0)$ or how far off it is from passing it $(M<0$ ).

An example is given in Figure 3 , where the degradation of the three breaker poles $(A, B$, and $C)$ is presented during a sequence of successive tests. It can be seen clearly that the margin of the breaker decreases with every test. The rate of margin decay (among others) is a measure of the endurance of the breaker with respect to this type of tests.

\section{Arc-Circuit Interaction Software}

At the final stage of the realization of digital testing, measured arc model parameters will be used as input for the arc model. Of course, this arc model behaves as a nonlinear element in the electrical circuit and must therefore be analyzed with a dedicated computer program. The analysis of arc-circuit interaction involving nonlinear clements in relation to stjff differential equations makes it necessary to perform the calculations with a variable step size and adjustable accuracy of the computed currents, voltages, and conductances. Because they have fixed step-size solvers, EMTP and comparable programs are less suitable for this purpose and therciore a new approach, the integration of clifferential algebraic equations (DAE) by means of the backward differentiation formulas (BDF) method, has been chosen in developing a 
new software package for electrical transients computation. This new transient program, XTrans, has been developed at the Delft University of Technology especially for arc-circuit interaction studles. The program runs on a PC with the MS-Windows operating system and works fully graphical, as shown in Figure 4. The program is in use at several high-power and high-voltage laboratories in the world.

The program makes use of libraries that contain information about the behavior of element models. The program structure is depicted in Figure 5. This structure has been realized with object-oriented programming. The compiled code of the element models is placed in dynamic link libraries (DLLs). The models are, therefore, separate from the main program, which makes it easy to create new models and use them in the main program.

A full working demonstration version of the XTrans program can be downloaded from the homepage of the electrical power systems group at the Delft University of Technology, http://eps,et.tudelft.nl.

\section{Applications of Digital Testing Influence of Parallel Capacitance}

Powerful possibilities with digital testing are created when the arc model, validated as described in the section on Measurements and Data Analysis, is coupled with a circuit analysis package. Then, the performance of a circuit breaker, the fingerprints of which were obtained from real tests, can be estimated in circuits other than the test circuit.

For example, the influence of various standard substation components on the breakers' capabilities can be estimated through digital testing.

Here the influence of a parallel capacitance is calculated (for example, the parasitic capacitance of a current transformer, CT) in the substation. In Table 1 , the performance of a short-line fault interruption is compared in the presence of two types of CTs: CT 1, having $200 \mathrm{pF}$ of parasitic capacitance, and CT' 2 , having $400 \mathrm{pF}^{2}$. These CTs can be located near the circuit breaker and remote (the latter implying an additional $50 \mu \mathrm{H}$ of busbar between CT and breaker). $A s$ a reference, the case without CT has a performance of 1.0 .

Table 1 shows that the clifference between the two types of CTs is rather snall when compared to the gain obtained by the CT that was installed to the breaker as closely as possible.

\section{Critical Line Length Determination}

One of the most severe currents for a circuit breaker to interrupt is the short-line fault (SLF). In the case of a short-line fault, the short-circuit point is on a high-voltage transmission line a few kilometers away from the breaker terminals. After current interruption, a very steep, triangular-shaped waveform (with a rate of rise of $5-10 \mathrm{kV} /$ microsecond) stresses the extinguishing medi- um between the contacts. The percentage SLF indicates to what extent the short-circuit current is reduced by the transmission line, e.g., a short-circuit current of $40 \mathrm{kA}$ is reduced to $36 \mathrm{kA}$ in case of a $90 \%$ SLF. In the IEC standard, $75 \%$ and $90 \%$ SLF tests are prescribed.

As an example of digital testing, the critical line length, the short-line fault percentage that stresses the circuit breaker most, will be determined for a $145 \mathrm{kV}$,

\begin{tabular}{|c|c|c|}
\hline \multicolumn{3}{|c|}{ Table 1. Influence of a current transformer } \\
\hline Performance & Near & Remote \\
\hline CT i (200 pF) & 1.9 & 1.2 \\
\hline CT $2(400 \mathrm{pF})$ & 2.4 & 1.4 \\
\hline
\end{tabular}

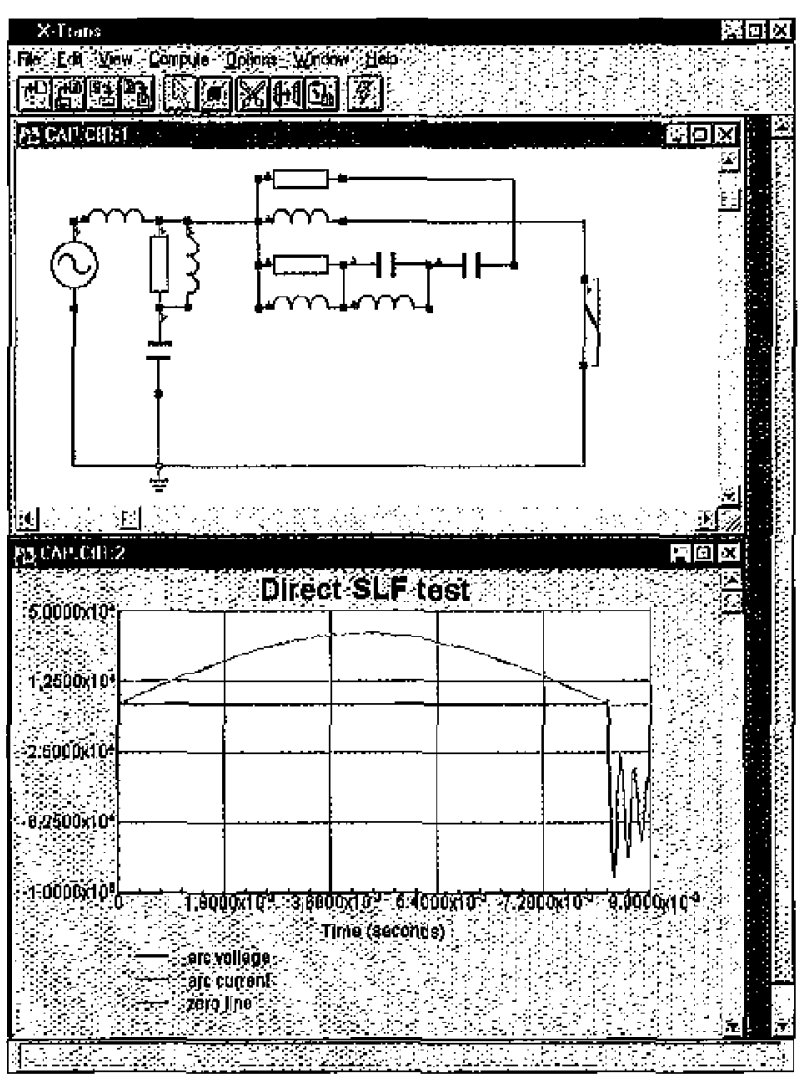

Figare 4. XTrans transient program

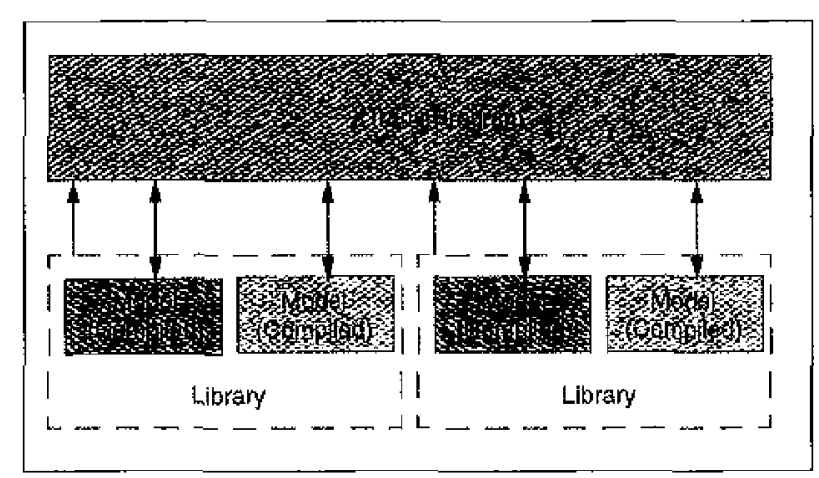

Figare 5. Structure of the XTrans transient program 


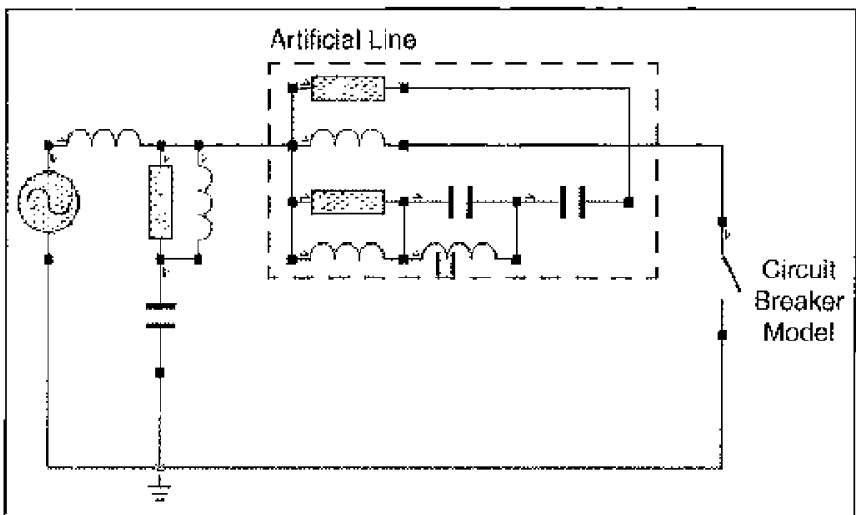

Figure 6. A direct SLF test circuit in the XTrans program

$31.5 \mathrm{kA}_{3} \mathrm{SF}_{6}$ circuit breaker. A direct SLF test circuit is shown in Figure 6, Three different indicators, active at different time intervals (before current zero, at current zero, and after current zero) are used to quantify the stress on the circuit breaker model.

- Before current zero: the time before current zero where the arc resistance cquals the surge impedance of the transmission line $t(R=Z)$, The closer the value is to current zero, the more severe the breaker is stressed by the test circuit.

- At current zero: the are resistance $R 0$. The lower the are resistance value at the current zero crossing, the stronger the breaker is stressed by the test circuit.

- After current zero; the post-arc energy Epa. This value is the integral of the multiplication of the small post-are current and the recovery voltage. It is clear that only for successful interruptions an tpa value can be calculated. The higher the Epa value is, the more severe the breaker is stressed by the test circuit.

The actual computation is based on 75 current zero recordings of the circuit breaker of which the circuit breaker model parameters have been determined. For ench sot of parameters, the stress at the various shortline fault percentages is computed. At last, the overall stress is visualized, which is shown in Figure 7.

All three indicators show that the circuit breaker model is stressed most severely at a $93 \% \mathrm{SI} . \mathrm{F}$, whereas a $90 \%$ SLF is prescribed in the IEC standard. This shows that digital testing can be applied to use the information olstained from laboratory tests for the development of fulure standards.

\section{Acknowledgments}

The authors are indebted to the lyirectorate General XII of the European Commission in Standards, Measurements, ancl 'lesting Pyogram for sponsoring. The effort of the other partmers involves in the projeet is greatly appreciated.

\section{For Further Reading}

R.1'P. Smeots, V. Kertész, "Lvaluation of high-vollage ctrcuit breaker performance with a now arc nodel," IEE Proceedings on Generation

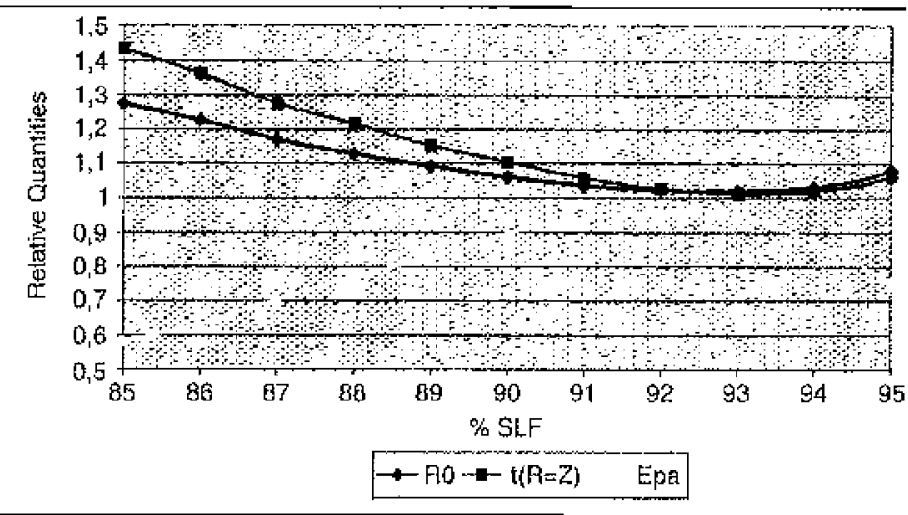

Figure 7. Critical line length determination by means of digital testit.

Transmission, and Distribution.

N.I.H. Bijl, L. van der Sluis, "New approach to the calculation of electrical transients," European Transactions on Electrical Pousr Eng:neering (ETEP), Volume 8, Number 3, pp. 175-179 and 181-186. May/June 1998.

\section{Biographies}

Pieter $\mathrm{H}$. Schavemaker obtainerl his $\mathrm{MSc}$ in electrical engineering from tho Delf University of Technology in 1994. Atter graduation, he performed rescarch on power system state estimation with the Power Systems laboratory. In 1995, he started as an application engineer programming Sulbstation Control Systems with AED in the Netherlands. Since 1996, he has been with the Power Systems I.ahoratory, where he is currently assistant prolessor. He is working on PhD rescarch on digital testing of high-voltage circuit breakers within the framework of a Luropean project. His main rosurch interests include power system transients and power system calculations. He is a member of IEEC. He can be reached by F-mail, P'.H.Schavemakeraits.tudelft, $\mathrm{sl}$.

Lou van der Sluis obtained his MSc in electrical engineering fron the Delft University of 'T'echology in 1974. He joined the KEMA High-Power Laboratory in 1977 as a test enginecr and was irvolved in the clevelopment of a data acquisition system for the High-Iower Laboratory, computer calculations of test circuits, and the analysis of tost data by digital computer. In 1990, he became a part-lime pro fessor, and, since 1492, he has been employer as a full-time professor at the Delft Univorsity of Technology in the Power Systems Department. He is a senior member of IFEE and convener of WG CC-03 of Clgre and Cired to stuly the transient recovery vollages in medium and high voltage networks. [le can be reached by ti-mail, LvanderSluis@its.tudelIt.nl.

René P.P, Sneets obtained his MSc in physics from the Eindhover University of Technology in 1981. Ho obtained the FhD degree in 1987 for research work on vacuum arcs at the same university. From 1983 to 1995 , ho was a stafi member of the Finergy Systems Dlvision of the Faculty of Electrical Engineering, Findhoven University. During the year 1991, te spent a sabbatical leave at Toshiba Corporation's Heavy Apparatus Engincering Laboratory in Jajan. In 1995, he joined KEMA for R\&D ol the High-Power Laboratory. Ile is a menber of Cigre WG 13.04 , the Current Zero Club, Clyre, and the IEEE. lle can be reached by l: mail, r.p.p.smeetsGkema.n.

Viktor Kertesz obtained his MSe in electryal engineerlng from Buclapest University of Technology in 1966, PhW in 1976, and DSc in 1989. He joined the High-Power Laboratory of the Hlectrical Power Research lnstitute, Budapest, as a researcher and test engineer in 1966. He became a professor of mathematics at the Budapest Uiviversity of T'echnology in I979 and has held the chair of full professor since 1989. He has had a scientiflc contact with KEMA in the field of crecuit breaker measuring problems and the analysis of arc phenomena since 1978. He contributed as a member to Cigre WG l:3,0l (arc nodeling). He can be reached by E-mail, kerteszyøelender.hu. 